\title{
Marketing Social - A Estratégia De Mudança Do Comportamento Social
}

\author{
Sônia de Oliveira Morcerf \\ sonia.oliveira@csn.com.br \\ Teresa Cristina Seabra \\ teresacristinaa@uol.com.br
}

\section{Resumo}

Ao longo dos anos, o marketing vem sofrendo inúmeras adaptações para se adequar às mudanças no cenário mundial e, desse modo, vem agregando novos recursos e fundamentos. Assim, é hoje um conjunto de conhecimentos essencial para profissionais das mais diversas áreas e interessa a todos que precisam promover bens, serviços, propriedades, pessoas, lugares, eventos, informações, idéias ou organizações.

Atualmente o marketing recebe vários adjetivos: cultural, ambiental, esportivo, social, entre outros. Neste trabalho focamos o Marketing Social, buscando conhecer os conceitos, definições e as várias aplicações que vêm sendo dadas no cenário brasileiro e como se relaciona com a Responsabilidade Social Empresarial. Procuramos entender um pouco melhor qual é o papel do Marketing Social, ressaltando tratar-se de uma estratégia de mudança comportamental na sociedade. O trabalho buscou também distinguir o Marketing Social da Responsabilidade Social das Empresas.

Palavras-chave: Marketing, Social , Comportamento e Responsabilidade Social

\section{1 - Introdução}

"Marketing é um processo social por meio do qual pessoas e grupos de pessoas obtêm aquilo de que necessitam e/ou desejam com a criação, oferta e livre negociação de produtos e serviços de valor com outros.” (Philip Kotler)

Existem várias definições para o marketing, em função deste ter ficado muito tempo vinculado à grande exposição da propaganda e da venda pessoal. Porém o marketing deve ser considerado no seu sentido mais amplo, que é como um processo de troca. Richers (1985), afirma que o marketing se processa através de atividades sistemáticas de uma organização humana voltadas à busca e realizações de trocas para com o seu meio ambiente, visando objetivos específicos. Essa troca deve ser sistemática, intencional e voltada para uma expectativa de resultados previsíveis, qualificáveis ou não.

As dificuldades em definir marketing têm origem na sua relação direta com vendas, e motivadas também, pelas modificações sofridas em seu conceito desde que foi determinado pela primeira vez, como ocorreu na década de 60, quando foi ampliado. Neste 
período, cresceu por parte de alguns administradores de organizações sem fins lucrativos (como museus, escolas, bibliotecas e hospitais) o interesse pelo marketing com o objetivo de manter suas organizações, que não possuíam grande ajuda do governo. Para essas organizações, o marketing seria uma forma de solucionar seus problemas. Naquele momento sua utilização por essas organizações atendeu a dois aspectos: um foi a promoção dessas organizações para um aumento de clientes (alunos, usuários, visitantes); e o outro foi a parceria com organizações com fins lucrativos para a promoção de mensagens sem fins lucrativos.

As trocas do marketing exercidas por organizações sem fins lucrativos são de bens intelectuais. Essa evolução do pensamento mercadológico nas organizações com e sem fins lucrativos levou à interação de técnicas e objetivos de marketing nas suas ações específicas, o que resultou na utilização do marketing institucional.

O marketing institucional apenas teve sua amplitude de funções e conceitos concretizada depois de um longo período de trocas ideológicas entre organizações com e sem fins lucrativos, e de ter havido um desenvolvimento conceitual da consciência mercadológica que era operada pelo marketing empresarial.

Para Rabaça (1994), o marketing institucional é uma modalidade do marketing que engloba uma série de outras, como o marketing social, cultural, o esportivo, o comunitário, o ecológico, e seu objetivo é a criação de atitudes favoráveis nos diversos segmentos do público em relação à empresa e à fixação da marca e da imagem corporativa. Alguns mercados, como os da cultura, do esporte, da promoção social e da ecologia, são áreas comuns aos interesses institucionais tanto das organizações com fins lucrativos, como das sem fins lucrativos.

Para Vaz (1995) marketing social é a modalidade de ação mercadológica institucional que tem como objetivo principal atenuar ou eliminar os problemas sociais, as carências da sociedade relacionadas principalmente às questões de higiene e saúde pública, de trabalho, educação, habitação, transportes e nutrição.

A sociedade espera resultados concretos, que transformem carência em atendimento e ausência em participação, interrompendo o ciclo vicioso da exclusão. Neste contexto, cada vez mais, são utilizados os métodos e técnicas de marketing social, que pode ser conceituado, segundo Kotler e Zaltman (apud Schiavo, 1999) como a criação, implementação e controle de programas voltados para influenciar a aceitabilidade das idéias sociais e envolvendo considerações de planejamento de produto, preço, comunicação, distribuição e pesquisa de marketing.

Para os autores o marketing social é um dos novos desenvolvimentos promissores, pelos quais se espera aumentar a eficácia de agentes sociais de mudança, no sentido de proporcionar as mudanças sociais desejadas.

\section{Objetivos}

O objetivo deste trabalho é promover uma reflexão sobre como vem sendo utilizado o conceito de marketing social, por meio do resgate de definições sobre o tema e sua aplicabilidade na realidade brasileira. empresas.

Subsidiariamente, distinguir marketing social da responsabilidade social das 


\section{2 - Metodologia}

O estudo foi desenvolvido por meio de revisão bibliográfica, incluindo obras de referência no marco teórico e artigos recentes publicados em periódicos e jornais de grande circulação. Toda a análise foi feita sob um enfoque crítico, refletindo sobre o uso e aplicabilidade deste conceito no contexto brasileiro.

\section{3 - Referencial Teórico}

\section{1 - Marketing e Marketing Social}

De acordo com Kotler (2004), normalmente o marketing é visto como a tarefa de criar, promover e fornecer bens e serviços a clientes, sejam estes pessoas físicas ou jurídicas. Na verdade, os profissionais de marketing envolvem-se no marketing de bens, serviços, experiências, eventos, pessoas, lugares, propriedades, organizações, informações e idéias.

Ainda segundo Kotler (2004), dentre todas as inúmeras definições existentes para marketing, podemos estabelecer uma distinção entre definições sociais e gerenciais. Uma definição social mostra o papel desempenhado pelo marketing na sociedade. Um profissional de marketing disse certa vez que o papel de marketing é "proporcionar um padrão de vida superior”. Uma definição social que serve a nosso propósito é: marketing é um processo social por meio do qual pessoas e grupos de pessoas obtêm aquilo de que necessitam e o que desejam com a criação, oferta e livre negociação de produtos e serviços de valor com outros. Quando se usa uma definição gerencial, o marketing é freqüentemente descrito como "a arte de vender produtos". Mas as pessoas se surpreendem quando ouvem que o mais importante em marketing não é vender! Vender á apenas a ponta do iceberg de marketing.

Segundo Drucker (apud Kotler, 2004), pode-se presumir que sempre haverá necessidade de algum esforço de vendas, mas o objetivo de marketing é tornar a venda supérflua. A meta é conhecer e compreender tão bem o cliente que o produto ou o serviço se adapte a ele e se venda por si só. O ideal é que o marketing deixe o cliente pronto para comprar.

Para Kotler e Fox (1994), marketing é a habilidade de planejar e administrar as relações de troca de uma instituição com seus vários públicos. É análise, planejamento, implementação e controle de programas cuidadosamente formulados para proporcionar trocas voluntárias de valores com mercados-alvo e alcançar os objetivos institucionais. Marketing envolve programar as ofertas da instituição para atender às necessidades e aos desejos de mercados-alvo, usando preço, comunicação e distribuição eficazes para informar, motivar e atender a esses mercados.

Ainda segundo a definição de Kotler e Fox (1994), um público é constituído de um grupo distinto de pessoas e/ou organizações que têm interesse real ou potencial em afetar uma instituição.

Para Kotler e Roberto (1992) o termo marketing social apareceu pela primeira vez em 1971, para descrever o uso de princípios e técnicas de marketing para a promoção de 
uma causa, idéia ou comportamento social. Desde então, passou a significar uma tecnologia de gestão da mudança social, associada ao projeto, implantação e controle de programas voltados para o aumento da disposição de aceitação de uma idéia ou prática social em um ou mais grupos de adotantes escolhidos como alvo.

Para Vaz (1995) Marketing social é a modalidade de ação mercadológica institucional que tem como objetivo principal atenuar ou eliminar os problemas sociais, as carências da sociedade relacionadas principalmente às questões de higiene e saúde pública, de trabalho, educação, habitação, transportes e nutrição.

Ainda de acordo com Vaz (1995) os programas baseados no marketing social são trabalhos cuidadosos de pesquisa, que procuram encontrar a raiz do problema social, identificando-se os focos de resistência a uma mudança (comportamental) e, então, definindo um planejamento de apresentação das idéias, de formulação das propostas e de preparação da estrutura necessária para dar sustentação à campanha.

Para Kozel (1997) o marketing social cria e administra todo o processo, cujas ações e resultados passam a construir valores que se agregam aos produtos. $\mathrm{O}$ assistencialismo, mesmo se efetuado de forma sistemática, pouco agrega ao conceito da empresa, pois ela não gerencia nem detém a autoria e o controle do processo.

Para Kotler e Roberto (1992) marketing social é uma estratégia de mudança de comportamento. Ele combina os melhores elementos das abordagens tradicionais da mudança social num esquema integrado de planejamento e ação, além de aproveitar os avanços na tecnologia das comunicações e na capacidade do marketing.

\section{2 - Responsabilidade Social Empresarial}

Segundo Martinelli (1997), a correta prática da responsabilidade social pode melhorar o desempenho e a sustentabilidade a médio e longo prazo da empresa, proporcionando: valor agregado à imagem corporativa da empresa; motivação do público interno; vantagem competitiva; facilidade no acesso ao capital e financiamento; reconhecimento dos dirigentes como líderes empresariais; melhoria do clima organizacional; dentre outros.

Argumentam também Melo Neto e Froes (2001) que as empresas socialmente responsáveis tendem a se destacar pelo seu padrão de comportamento ético-social, demonstrando comprometimento com a comunidade local e com seus funcionários, por meio de ações sociais cujo principal objetivo não é o marketing, mas o desenvolvimento local. Como uma tentativa de contextualizar as ações de responsabilidade social, os autores mostram que há, atualmente, predominância de ações sociais externas (voltadas para a sociedade ou para a comunidade local) sobre as de caráter interno (cujo alvo são os funcionários e seus familiares); que grandes organizações criaram suas fundações e atuam socialmente na área de educação, como é o caso da Fundação Bradesco; e que ainda prevalece em nosso país o padrão assistencialista em ações sociais, em especial junto a empresas de pequeno e médio porte, apesar de as grandes empresas já terem identificado a importância de ações sociais sustentáveis.

De acordo com Cappellin e Giuliani (1999) na busca de eficiência e excelência empresarial, parece não ser mais satisfatória a tradicional alquimia do cálculo custobenefício com o aumento da produtividade e a ampliação das vendas no mercado. Os critérios de avaliação do sucesso começam a incorporar dimensões que vão além da 
organização econômica e que dizem respeito à vida social, cultural e à preservação ambiental. Pode-se dizer que a eficiência não é só 'fazer as coisas bem', segundo as regras de mercado, mas é 'fazer as coisas boas', segundo princípios éticos.

Segundo Robert Dunn (1998), presidente do Business for Social Responsability (BSR), organização norte-americana sem fins lucrativos dedicada à divulgação da responsabilidade social nos negócios, "ser socialmente responsável é um dos pilares de sustentação dos negócios, tão importante quanto a qualidade, a tecnologia e a capacidade de inovação. Quando a empresa é socialmente responsável, atrai os consumidores e aumenta o potencial de vendas, gerando maiores lucros para os acionistas. Além disso, também é, hoje, um sinal de reputação corporativa e da marca.”

\section{4 - Resultados e Discussão}

\section{1 - Marketing - O que é e o que não é?}

Hoje o marketing entrou em praticamente todas as esferas de nossa vida. Fazer marketing é criar as condições ideais para que nosso produto, serviço ou mensagem alcance seu objetivo, não importa se estamos falando de uma venda ou da simples necessidade de se convencer alguém de algo.

A expressão "marketing” vem sendo amplamente utilizada, não apenas no campo dos negócios, mas também na área social. Contudo, o exato significado do termo ainda é pouco conhecido, o que justifica algumas conceituações. Para a American Marketing Association, marketing é o desempenho das atividades que dirigem o fluxo de bens e serviços do produtor ao consumidor. É o processo de planejamento e execução de criação, estabelecimento de preço, promoção e distribuição de idéias, produtos e serviços para criar intercâmbios que irão satisfazer as necessidades do indivíduo e da organização.

Drucker (apud Kotler, 2004) por sua vez, apresenta uma definição mais direta: marketing é todo o empreendimento do ponto de vista do consumidor. Para Mc Carthy, que o dividia em duas grandes áreas, marketing é um processo social que dirige o fluxo de bens e serviços dos produtores para os consumidores, de maneira a equilibrar a oferta e a procura, e visando alcançar os objetivos da sociedade.

Finalmente, Kotler (2004), conceitua o marketing como sendo a análise, o planejamento, a implementação e o controle de programas e/ou projetos formulados para propiciar trocas voluntárias de valores com mercado-alvo, com o propósito de atingir objetivos operacionais concretos. Portanto, para execução de um plano de marketing, há que se levar em conta as necessidades e desejos do mercado, além do uso efetivo de técnicas de preço, comunicação e distribuição, para informar, motivar e servir ao respectivo mercado. Outras definições poderiam ser transcritas porém, pouco acrescentariam à compreensão do termo.

Considerando, no entanto, a grande e crescente popularização do termo, talvez seja útil discutir um pouco daquilo que o marketing, efetivamente, não é. De acordo com Schiavo (1999) com freqüência, utilizam-se expressões como: isso é apenas, uma jogada de marketing; é preciso fazer marketing; ou, até mesmo, isso não passa de marketing. É como se a situação da qual se fala, de fato, não existisse. Com efeito, usa-se o termo marketing nos mais diferentes contextos, mas sem muita preocupação com a sua aplicabilidade. Por isso, convém esclarecer que: 
- Marketing não é promoção - É muito comum o uso minimizado do conceito de marketing, considerando-o sob a perspectiva de apenas um dos seus principais componentes: a promoção ou publicidade. Nesse caso, “fazer marketing” seria o mesmo que promover um produto, idéia e/ou serviço.

- Marketing não é aparecer na mídia - Outra confusão é pensar que marketing se restringiria a dar visibilidade a algum produto, serviço, idéia ou uma causa, aumentando a sua exposição quantitativa e/ou qualitativa nos diversos meios de comunicação. Isso é, sim, uma estratégia de marketing

- Marketing não é venda - Quando se lê um anúncio buscando um gerente de marketing, pode-se ter a certeza de que não se requer apenas um profissional de vendas. Mais que isso, a empresa busca alguém capaz de trabalhar seus produtos desde a fase de concepção, passando pela produção, apresentação, definição de preço, estratégia promocional e colocação nos pontos-de-venda, até a etapa de consumo, privilegiando-se o ponto-de-vista do consumidor.

- Marketing não é mágica - Ilusionismo não combina com o mercado. Também no marketing, é aplicável a idéia de que "não se pode enganar a todos por todo tempo". No marketing, não há soluções fáceis, de curto prazo e/ou baixo custo, em si-mesma. A criatividade empresarial e/ou do empreendedor, sem dúvida, é fator fundamental para o êxito de um plano de marketing, mas não faz milagres. Fazer o melhor por menos é o que se espera de qualquer profissional em uma organização. Soma-se o fato de que, no mercado globalizado, é cada vez mais imprescindível dispor de bons produtos e/ou serviços de qualidade a preços acessíveis para os mercados-alvo. O feeling de um profissional pode constituir o diferencial para que se alcancem ou se consolidem vantagens competitivas. No entanto, esse fator não poderá substituir uma boa pesquisa mercadológica, que oferece respostas científicas para as questões concretas.

\section{2 - Marketing Cultural e Ambiental}

Atualmente o termo marketing vem recebendo várias complementações que buscam definir melhor sua área de atuação. Assim, encontramos o marketing associado à cultura, ao meio ambiente, ao social, entre outros.

Marketing cultural é uma ferramenta de comunicação, muito útil para agregar valor à imagem das empresas que proporcionam os recursos, monetários, intelectuais e até mesmo morais, para a execução de projetos pertinentes à sociedade.

É considerado marketing cultural, toda ação de marketing que usa a cultura como veículo de comunicação para se difundir o nome, produto ou fixar imagem de uma empresa patrocinadora.

A estratégia de marketing cultural torna-se viável justamente quando visa estabelecer um eixo de identidade entre quem consome determinada marca e quem gosta de determinada arte. Apesar do desconhecimento de muitos, o marketing cultural já é praticado com certa regularidade por alguns setores no Brasil e em pleno vapor em outros países, representando mais um instrumento de informação junto ao consumidor, arma que 
os produtores culturais não podem dispensar. De acordo com Cândido José Mendes de Almeida, organizador do livro Marketing cultural ao vivo - depoimentos (Ed. Francisco Alves, 1992), "a química do marketing cultural consiste na capacidade de um projeto cultural em transportar uma informação de um universo, que é o público que consome aquele produto cultural, para um outro universo, que é o público consumidor do produto ou do serviço daquela empresa patrocinadora”.

O marketing ambiental apresenta-se como uma ferramenta capaz de projetar e sustentar a imagem da empresa, difundindo-a com uma nova visão de mercado, destacando sua diferenciação ecologicamente correta junto à sociedade, fornecedores, funcionários e ao mercado. O marketing ambiental também é conhecido como marketing verde, ecologicamente correto ou ecomarketing. Extrapola a mera publicidade ou divulgação dos produtos ou serviços oferecidos por empresas que querem veicular na mídia e no meio profissional ou para o consumidor a aplicação de métodos ambientalmente corretos aplicados ao seu gerenciamento interno ou na produção ou prestação de serviços.

\section{3- Marketing Social}

Para Schiavo (1999) com o crescimento do Terceiro Setor e sua profissionalização, pouco a pouco, as modernas técnicas de gestão foram incorporadas à área social. A gerência por intenções não tem mais espaço: a sociedade espera resultados concretos, que transformem carência em atendimento e ausência em participação, interrompendo o ciclo vicioso da exclusão. Neste contexto, cada vez mais, são utilizados os métodos e técnicas de marketing social - que pode ser conceituado, segundo Kotler (2004), como a criação, implementação e controle de programas voltados para influenciar a aceitabilidade das idéias sociais e envolvendo considerações de planejamento de produto, preço, comunicação, distribuição e pesquisa de marketing.

Para eles, o marketing social é um dos novos desenvolvimentos promissores, pelos quais se espera aumentar a eficácia de agentes sociais de mudança, no sentido de proporcionar as mudanças sociais desejadas. Diversos outros autores defendem a aplicação, na área social, dos princípios de marketing utilizados pelas empresas com fins de lucro. Em resumo, recomendam que as organizações do Terceiro Setor incorporem a seus quadros um profissional de marketing que identifique os mercados em que a organização atua, os seus públicos-alvo e os respectivos segmentos; que busquem analisar e conhecer o comportamento da população que se pretende atingir; estabelecer o posicionamento que a causa social a ser promovida deverá ter na mente do adotante; propor produtos sociais apropriados às mudanças pretendidas; além de estabelecer o marketing mix da organização. Esse profissional também deve responsabilizar-se pelas ações de marketing, avaliar os resultados e proceder às correções necessárias ao êxito do empreendimento social desenvolvido pela organização. Sem dúvida, mesmo na área social, uma organização deve começar e terminar todo o seu trabalho num mesmo ponto: o cliente.

O marketing social é, portanto, uma nova tecnologia de administração da mudança social, associada ao projeto, à implantação e ao controle de programas voltados para o aumento da disposição de aceitação de uma idéia e/ou prática social em um ou mais grupos adotantes selecionados como alvo. Assim, deve-se empregar os conceitos de segmentação do mercado, pesquisa de consumidores, desenvolvimento e testes de conceitos ou produtos, comunicação direta, de facilitação, incentivos e teoria da troca. Tudo isso visando maximizar a 
resposta dos adotantes selecionados como alvo. Neste caso, a organização busca os objetivos de mudança na crença de que, deste modo, contribuirá para o desenvolvimento individual e social.

Mendonça e Schommer (2000) e Schiavo (1999) citam esse aspecto definido por Atucha, para quem a expressão marketing social é empregada para descrever o uso dos princípios e técnicas para a promoção de uma causa, idéias ou um comportamento social. É uma tecnologia de administração da mudança social associada ao projeto de implementação e controle de programas destinados a aumentar a disposição das pessoas para a aceitação de uma idéia, um comportamento e/ou uma prática social. Ainda de acordo com Atucha, o marketing social é uma ferramenta democrática e eficiente, que aplica os princípios e instrumentos de marketing, criando e outorgando maior valor à proposta social. Por meio dele, redescobre-se o consumidor através de um diálogo interativo, o que permite um processo de reflexão, participação e mudança social. Os resultados são mensuráveis pelos seus efeitos e podem ser avaliados por sua eficácia, eficiência e efetividade.

Segundo dados de uma pesquisa realizada pelo IPEA - Instituto de Pesquisa Econômica Aplicada - existe um número crescente de empresas que estão investindo no social. O interessante a ressaltar é que, a maioria das empresas investe sem realizar um estudo e controle sobre seu investimento. Ou seja, o fazem por filantropia. Em outros países, as empresas estão vinculando suas marcas a uma causa de interesse social mediante acordo com entidades sem fins de lucro, que desenham e executam os programas de ação.

No entanto, o problema maior das empresas é identificar aquela causa de interesse social mais relevante para seu público objetivo e que seja coerente com os valores da marca. Em primeiro lugar é necessário identificar os valores da marca e os valores do consumidor dessa marca, produto ou serviço. O seguinte passo consiste em distinguir aquelas causas que melhor poderão representar os valores entre cliente e empresa.

O marketing social inicia-se como uma verdadeira forma de exercício de responsabilidade social, e pode chegar a construir a longo prazo um valor diferencial para a marca e uma vantagem competitiva para as empresas. Hoje em dia existem conhecimentos e técnicas para organizar e colocar em prática programas efetivos de mudança social em qualquer área de assunto social, tanto local como nacional. Originar a mudança social que melhore a qualidade de vida da população é um desafio das campanhas sociais e o objetivo do marketing social.

Os resultados da aplicação do Marketing Social, por sua vez, pretendem atingir quatro tipos de mudanças sociais, podendo uma causa, em qualquer momento, procurar produzir uma ou mais dessas mudanças.

A primeira delas é a de natureza cognitiva, quando são estabelecidos programas de informação pública ou de educação pública. São elas: campanhas para explicar o valor nutritivo de diferentes alimentos; campanhas para explicar o trabalho de órgãos governamentais voltados à saúde pública; campanhas para chamar a atenção aos problemas sociais, como a pobreza, a intolerância ou a poluição.

A segunda é a mudança de ação, quando são promovidas campanhas para influenciar pessoas a comparecer a uma imunização em massa; campanha para atrair mulheres acima de quarenta anos a realizar exames de prevenção de câncer; campanha para atrair novamente às escolas, os estudantes que deixaram de estudar; campanhas para levantar grandes quantidades de dinheiro para fins de assistência social; campanhas para atrair doadores de sangue ou doação de órgãos. 
As causas de mudança de ação apresentam-se com maiores dificuldades de serem levadas ao término, em relação às causas de mudanças cognitivas, porque o mercado-alvo terá de aprender alguma coisa, diferente de seu repertório normal, e efetuar uma ação específica baseada naquilo que foi aprendido. A ação envolve um custo para a pessoa e mesmo que a sua atitude quanto à ação seja positiva ou favorável, sua concretização poderá ser dificultada, ou ainda impedida, por fatores como a distância, o tempo, as despesas ou até a inércia, fruto do conformismo.

Outra classe de causa social visa induzir ou ajudar as pessoas a mudança de comportamento, tendo em vista o bem-estar individual. O comportamento normal das pessoas é sabidamente prejudicial à saúde, porém a pessoa não é capaz ou não está disposta a tomar as medidas necessárias para mudar seu comportamento. Essas causas incluem esforços para diminuir o vício de fumar, esforços para desencorajar o consumo de álcool, esforços para desmotivar o uso de entorpecentes e esforços para mudar hábitos alimentares.

A mudança de comportamento é mais difícil de ser alcançada do que as mudanças cognitivas ou mudanças que exigem uma única ação. Muitas vezes a pessoa está consciente dos efeitos prejudiciais de seus hábitos de consumo, mas não existe uma ação única que ela possa adotar a fim de terminar de uma vez por todas com as tentações a que está sujeita. O desafio será auxiliá-la a mudar completamente a rotina de comportamentos que se encontra enraizada em seus sistemas.

A mudança de valor, última a ser considerada no Marketing Social, compreende esforços para alterar as idéias que as pessoas têm sobre o aborto, esforços para modificar a postura em relação ao número de filhos que deveriam ter, esforços para aumentar a participação e o respeito ao trabalho feminino, esforços voltados à preservação dos bens públicos por parte das pessoas, e outros que lidam com os aspectos práticos da intolerância e da baixa qualidade de participação do cidadão na comunidade, compreendendo as causas mais difíceis de serem levadas a efeito.

Essas mudanças se chocam com o sentido de identidade e bem-estar de um indivíduo que está cristalizado em seus valores básicos, os quais orientam suas percepções e escolhas sociais, morais e intelectuais. A intromissão de dissonância em seu conjunto de valores criará um intenso constrangimento e estresse. Ele procurará evitar as informações dissonantes, ou irá desprezá-las pela racionalização, ou as colocará de lado para que não afetem seus próprios valores.

Deve-se, então, entender o Marketing Social, desde que devidamente controlado e avaliadas as suas conseqüências, como um instrumento colocado à disposição de todos os agentes preocupados com as alterações necessárias no tecido social, para que, numa sociedade democrática, suas intenções sejam aceitáveis em termos éticos e sociais. Então, não será somente com a comunicação de caráter persuasivo que essas pessoas passarão a adotar e observar as normas de segurança. A perfeita formação de uma opinião, não mais um sentimento, é que permitirá atingir o resultado de mudança.

\section{3 - Responsabilidade Social}

O Instituto Ethos defende que a Responsabilidade Social Empresarial é uma forma de conduzir os negócios da empresa, tornando-a parceira e co-responsável pelo desenvolvimento social. A empresa "socialmente responsável" é aquela que possui a capacidade de ouvir os interesses das diferentes partes (acionistas, público interno, 
fornecedores, consumidores, comunidade, meio ambiente, governo e sociedade) incorporando-os, ao planejamento de suas atividades, buscando atender às demandas de todos, não apenas dos acionistas ou proprietários.

A Comissão das Comunidades Européias preconiza que Responsabilidade Social Empresarial é um comportamento que as empresas adotam voluntariamente, indo além dos requisitos legais, porque consideram ser esse o seu interesse em longo prazo. Implica uma abordagem por parte das corporações que coloca no cerne das estratégias empresariais as expectativas de todas as partes envolvidas e o princípio de inovação e aperfeiçoamento contínuos.

Independente de definições e conceitos, o fato é que vivemos um momento em que as empresas e a sociedade se mobilizam para buscar soluções a fim de diminuir as desigualdades sociais.

As empresas se envolvem em atividades sociais, demonstrando que se preocupam não só em produzir bens e serviços, mas também em buscar o bem estar social através da valorização do homem, do meio ambiente e da cultura. Esses elementos são fatores determinantes do sucesso mercadológico para as empresas buscam vincular sua imagem á noção de responsabilidade social. "A nova postura da empresa cidadã baseada no resgate de princípios éticos e morais passou a ter natureza estratégica”. Pode-se dizer que a eficiência não é só "fazer as coisas bem", mas "fazer as coisas boas", segundo princípios éticos.

Os investimentos sociais na própria empresa também são de suma importância para a sobrevivência no mundo atual. A empresa deve investir na educação e no progresso de seus funcionários, na saúde, na alimentação, enfim, através desses trabalhos, a empresa tende a colher mais em produtividade, compromisso e dedicação. Além disso, não se pode esquecer do meio ambiente e da comunidade.

Empresa que cumpre seu papel social, atrai mais consumidores e está investindo na sociedade e no próprio futuro.

Uma pesquisa realizada pelo Instituto Ethos descreve os aspectos mais importantes, sob a ótica dos consumidores e clientes, para julgar se uma empresa conduz adequadamente seus negócios, com base nos parâmetros da Responsabilidade Social Empresarial:

- Tratamento dos funcionários e ética nos negócios: filosofia de tratamento dos funcionários e sindicatos, empregos de qualidade, saúde e segurança dos funcionários, mãos de obra infantil e barata, comportamento ético, honesto, obedece as leis, não participa de subornos e corrupção $51 \%$

- Impacto ambiental: histórico de poluição, dedicação à melhoria do meio ambiente e à preservação dos recursos naturais, produtos "verdes", apoio à reciclagem..........................4\% - Responsabilidade para com a sociedade num sentido mais amplo: não visa somente seus próprios interesses; ajuda a melhorar o mundo; dedicada ao nosso país, á comunidade local, aos direito humanos e causas nobres; respeita a cultura local e suas tradições; escuta os cidadãos locais....................................................................................................... 2\%

- Qualidade, imagem, prestígio, nome, reputação da marca: qualidade e preço de produto; familiaridade com os nomes de suas marcas, o que as pessoas comentam sobre esta empresa, propaganda, como eles tratam os clientes, sua história. $.34 \%$

- Fatores econômicos/financeiros/tamanho: volume em dólar; contribuição para a economia nacional/local; número de empregos gerados; tamanho do lucro; desempenho no mercado de ações; subsídios de governo. $.9 \%$ 
- Estratégia e gerenciamento dos seus negócios: uma estratégia inteligente, bom gerenciamento, um diretor/presidente respeitado, visão global e sucesso....................... 4\%

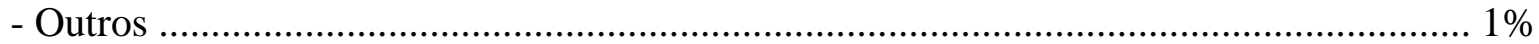

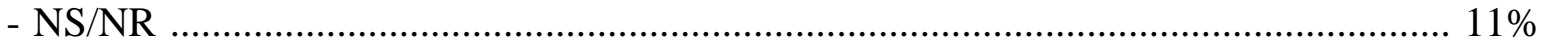

Base 2002 - Fonte: Instituto Ethos / Valor

A busca de certificação social também tem contribuído como diferencial competitivo para as empresas. Um empresário do setor industrial implementou uma política social, com alterações de seu sistema de produção, com a finalidade de reduzir os problemas externos e internos de sua empresa, e de seus empregados. Resolveu instituir um código de conduta para a certificação conforme a norma SA 8000. Ele constatou que, após a implementação de mudanças, para se adaptar aos parâmetros da Responsabilidade Social, sua produtividade aumentou, uma vez que a porcentagem de reclamações, sobre produtos defeituosos, baixou de $13 \%$ para $0,5 \%$. Disse: “... vendendo $12 \%$ a mais do produto, a implementação dessa norma, mais que vale pela mudança do sistema”.

Casos como esse demonstram que a responsabilidade social vem se tornando uma grande oportunidade para os negócios das empresas. Além de ser muito importante trabalhar a responsabilidade externa (ter uma relação ética com a comunidade em geral e local, investimentos sociais e transparência econômica), há de preocupar-se também com questões que a empresa enfrenta em seu dia a dia, tais como as condições de trabalho, compromisso com o desenvolvimento, política de contratações, entre outras. Enfim, a responsabilidade social não representa apenas o investimento social privado, aquele realizado por meio de projetos sociais na comunidade, mas sim uma nova postura da organização frente aos seus diversos públicos, internos e externos, incluindo empregados, fornecedores, acionistas, clientes e consumidores, meio ambiente, comunidade e até concorrentes.

A Fundação Abrinq vêm certificando algumas empresas que não trabalham com mão de obra infantil, incluindo seus fornecedores. Isso faz com que as empresas busquem parceiros que também estejam preocupados com essa questão social.

Dados da pesquisa Ethos/Valor mostram que 53\% dos entrevistados boicotariam os produtos de uma empresa que utilize a mão-de-obra infantil. Um exemplo clássico disso é o que ocorreu com a empresa americana NIKE, acusada de empregar mão-de-obra infantil em suas fábricas no território asiático, tendo que realizar um grande planejamento estratégico para que essa imagem negativa fosse eliminada do mercado.

Para os conceitos de Responsabilidade Social não basta que uma organização não admita o trabalho infantil ou a utilização do trabalho similar ao escravo. A organização deve ir além, se preocupando com toda a sua cadeia produtiva, cobrando dos seus fornecedores, a mesma postura que adota em sua empresa.

Fica claro, portanto, que Responsabilidade Social Empresarial está intimamente relacionada com a qualidade das relações que a empresa estabelece com seus stackholders partes interessadas - na condução de seus negócios.

\subsection{1 - O marketing Social e a Responsabilidade Social}


Pesquisas recentes (IPEA, SEBRAE E ETHOS), trazem dados cada vez mais otimistas da atuação das empresas socialmente responsáveis. Muito se fala em responsabilidade Social e Marketing Social. Entretanto, muitas empresas ainda não sabem como fazer essa diferenciação temática, e mais, não sabem como a Responsabilidade Social poderá representar uma oportunidade de negócio para sua organização.

A grande diferença entre o Marketing social e responsabilidade social é que o marketing social tem como objetivo a mudança de comportamento da sociedade para com o bem-social, utilizando ferramentas mercadológicas e técnicas de Marketing. A responsabilidade social, como vimos anteriormente, é a preocupação que as empresas, pessoas e governo têm pelo social. A responsabilidade social veio para ficar e tem se transformado em um novo critério de excelência e qualidade para as empresas. O marketing social deve ser incorporado à estratégia da empresa, no atual ambiente mercadológico, no qual o processo de globalização figura como mais um desafio a ser vencido pelas corporações, na busca por novos mercados e investimentos, onde a reputação é muito requerida e valorizada. A sociedade está mais ativa, e isto exige que as companhias interajam mais com seus públicos, gerenciamento sua marca, como forma de abrir novos canais de comunicação com a sociedade.

As organizações devem aspirar aos valores dos clientes e não o contrário. Compartilhar valores é uma necessidade para as empresas que queiram continuar sendo bem aceitas pelos consumidores. Neste contexto o marketing social se torna imprescindível. As empresas precisam entender que a responsabilidade social é uma forma de gerenciamento dos negócios e o marketing social é a conseqüência deste gerenciamento. Segundo Kotler (1999) o marketing social é uma estratégia de mudança de comportamento. Ele combina os melhores elementos das abordagens tradicionais da mudança social em um esquema integrado de planejamento e ação, além de aproveitar os avanços na tecnologia das comunicações e na capacidade do marketing.

O marketing social será implementado com sucesso em organizações que passarem por uma mudança de comportamento, valores e cultura, com base nos princípios éticos da responsabilidade social, em todo processo produtivo, administrativo e comercial para que possa refletir no mercado uma imagem positiva.

\section{5 - Conclusão}

Por todo exposto conclui-se que o marketing social deve decorrer, realmente, das ações efetivas das empresas socialmente responsáveis. Ou seja, o marketing social não é um fim em si mesmo, mas conseqüência de ações, atitudes e gerenciamento de processos das organizações com base nos princípios e valores preceituados por essa nova forma de gestão dos negócios das organizações - a responsabilidade social Empresarial.

Por seu caráter abrangente, a responsabilidade social empresarial apresenta uma efetividade da atuação social e de transformação da realidade excludente, uma vez que contempla todos os públicos da empresa - acionistas, empregados, comunidade, meio ambiente, fornecedores, consumidores e clientes e até concorrentes.

O marketing social é, portanto, uma nova tecnologia de administração da mudança social. Assim, deve-se empregar os conceitos de segmentação do mercado, pesquisa de consumidores, desenvolvimento e testes de conceitos ou produtos, comunicação direta, de 
facilitação, incentivos e teoria da troca. Tudo isso visando maximizar a resposta do públicoalvo selecionado.

Esse aspecto é ressaltado por vários autores neste trabalho, onde a expressão marketing social é empregada para descrever o uso dos princípios e técnicas para a promoção de uma causa, idéias ou um comportamento social. É uma tecnologia de administração da mudança social associada ao projeto de implementação e controle de programas destinados a aumentar a disposição das pessoas para a aceitação de uma idéia, um comportamento e/ou uma prática social. O marketing social é uma ferramenta democrática e eficiente, que aplica os princípios e instrumentos de marketing, criando e outorgando maior valor à proposta social. Por meio dele, redescobre-se o consumidor através de um diálogo interativo, o que permite um processo de reflexão, participação e mudança social. Os resultados são mensuráveis pelos seus efeitos e podem ser avaliados por sua eficácia, eficiência e efetividade.

\section{Referências Bibliográficas}

AMARAL, Sueli Angélica do. Marketing em unidades de informação: estudos brasileiros. Brasília: SENAI/IBICT, 1992.

BOONE, Louise. Marketing contemporâneo. 8ª ed., Rio de Janeiro: LTC, 1998.

CAPPELLIN, Paola \& GIULIANI \& Gian Mario. Compromisso social no mundo dos negócios. In: Boletim do Ibase Orçamento e Democracia, nº 11, fev/1999, p.10-11)

COELHO, Teixeira. Dicionário crítico de política cultural. São Paulo: Iluminuras, 1997.

CUCHE, Denis. A noção de cultura nas ciências sociais. São Paulo: EDUSC, 1999.

DUNN, Robert. Quer uma vantagem competitiva? Revista Exame, 669, ano 32, $\mathrm{n}^{\mathrm{o}}$ 18, 26/08/1998, p.5.

ETHOS. Instituto Ethos de Empresas e Responsabilidade Social. Apresenta informações institucionais e sobre responsabilidade social. Disponível em $:<$ http://www.ethos.org.br $>$. Acesso em: 15 outubro 2005.

FISHER, Fernando. Marketing cultural: uso e prática em empresas brasileiras. Rio de Janeiro, 1998. 198 f. Tese (Mestrado em Administração) - Instituto de Pós-Graduação e Pesquisa em Administração - COPEAD, Universidade Federal do Rio de Janeiro.

KOTLER, P.; FOX, K. F. A. Marketing estratégico para instituições educacionais. São Paulo: Atlas, 1994.

KOTLER, Philip. Marketing essencial.. São Paulo: Pearson Brasil, 2004.

KOTLER, Philip e ROBERTO, Eduardo. Marketing Social: Estratégias Para Alterar o Comportamento Público. Rio de Janeiro, Campus, 1ª . ed., 1992, p. 25. 
KOZEL JÚNIOR, José. O Top do Marketing Brasileiro. São Paulo, Scipione, 1ª ed., 1997, p. 214.

MARTINELLI, Antonio Carlos. Empresa - Cidadã: Uma Visão inovadora para uma ação transformadora. In: IOSCHPE, Evelyn Berg (org.). $3^{\circ}$ Setor: Desenvolvimento Social sustentado. Rio de Janeiro: Paz e Terra, 1997.

MELO NETO, Francisco Paulo de e FROES, César. Gestão da responsabilidade social Corporativa: o caso brasileiro. Rio de Janeiro: Qualitymark, 2001.

MENDONÇA, P. M. E.; SCHOMMER, P. C. O Marketing e suas Relações com o Social: Dimensões Conceituais e Estratégicas, CD-ROM, Encontro da Associação Nacional dos Programas de Pós-Graduação em Administração (ENANPAD), 24. 2000, Anais..., Florianópolis: ANPAD, 2000.

MUYLAERT, Roberto. Marketing cultural e comunicação dirigida. São Paulo: Globo, 1993.

PIMENTEL, Cléa D. P. "Técnicas de marketing aplicadas à biblioteca". Trabalho apresentado no Encontro Pernambucano de Biblioteconomia e Ciência da Informação, 1. Recife, 1982. In: SILVEIRA, A; AMARAL, S. A comp. Marketing em unidades de informação: estudos brasileiros. Brasília: IBCT/SENAI, 1993. pp. 177-190, 356.

RABAÇA, Carlos. Dicionário de comunicação. São Paulo: Ática, 1987.

SANTOS, José Luís dos. O que é cultura. São Paulo: Brasiliense, 1989.

SCHIAVO, Marcio Ruiz. Conceito e evolução do marketing social. Conjuntura Social. São Paulo. ano 1, n. 1 p. 25-9, mai. 1999.

VAZ, Gil Nuno. Marketing institucional. São Paulo: Pioneira, 1993.

Pioneira, 1995.

Marketing institucional: O mercado de idéias e imagens. São Paulo,

\section{Informações bibliográficas:}

Conforme a NBR 6023:2002 da Associação Brasileira de Normas Técnicas (ABNT), este texto científico publicado em periódico eletrônico deve ser citado da seguinte forma: MORCERF, S. O.; ALMEIDA, T. C. S.. Marketing Social - A Estratégia De Mudança Do Comportamento Social. Cadernos UniFOA, Volta Redonda, ano 1, nº. 1, jul. 2006. Disponível em: <http://www.unifoa.edu.br/pesquisa/caderno/edicao/01/71.pdf> 